\title{
Stair width, pitch and alignment in stair climbing and descending rates
}

John Zacharias ${ }^{\mathrm{ab}}$ and Guoqing $\mathrm{Lu}^{\mathrm{a}}$

${ }^{a}$ Laboratory for Urban Process Modelling and Applications

Peking University

Beijing, PR China

${ }^{\mathrm{b} C}$ Corresponding author: zachariasjohn478@gmail.com

Peking University, 7 Yihe Road, Haidian District, Beijing, PRC 1100871

Keywords: architecture; behavior change; public space; stair climbing; spatial cognition

\begin{abstract}
Innovative interventions in the planning and design of stair and escalator facilities call for understanding their effects on stair use. This study considers five planning variables for the twinned stair and escalator facilities-stair pitch and width, angle of deviation, height, and separating distance. Public sites were identified in 8 commercial districts in Beijing. Facilities $(n=21)$ presenting heterogeneously across variables were sampled for simultaneous up and down pedestrian counts in 185 -minute video segments middays, for a total of 1464 counts. Stair width accounts for $20 \%$ of the variance in ascending rate and 10\% in descending. Plan angle accounts for $2 \%$ in ascending and $5 \%$ in descending, while pitch accounts for $1 \%$ in ascending and $5 \%$ in descending. The study confirms the effects of layout and design of stairway and escalator facilities on facility choice. The results point directly to interventions in support of higher stair-climbing rates.
\end{abstract}

\section{Introduction}

Using stairs to change levels is advocated in daily routine travel on foot for its contribution to raising activity levels in sedentary urban populations, since stair climbing counts as vigorous exercise. The threshold for vigorous exercise, hence contribution to cardiorespiratory fitness, is reached after a vertical displacement of about $6 \mathrm{~m}$ (Allison et al., 2016). The recent literature abounds in studies on the health-enhancing effects of stair climbing. Muscle strength and endurance improved after a training program that included stair-climbing (Hongu et al., 2019). Stair climbing in naturalistic settings improved energy levels in all participants with males also showing improved cognitive performance (Stenling et al., 2019). The contributions are varied in focus and health component, all tending in the direction of moderate to strong positive effects.

How can stair use be increased? Point-of-decision prompts are effective interventions at least in the short term, and especially in public settings (Landais et al., 2020; Jennings et al., 2017; Puig-Ribera et al., 2019). Prompts to use stairs at worksites show mixed results with negative effects (Åvitsland et al., 2017), positive effects (Bellicha et al., 2016) and with most studies showing increased stair climbing during intervention (Soler, 2010). Training programs may result in increased stair-climbing when feelings of self-efficacy are enhanced (Hongu et al., 2019), or where short-term benefits from stair-climbing are emphasized, rather than longer term health benefits (Allais et al., 2017). Improving the visibility of the stairway alternative, using only visual information, results in $6 \%$ increase in the 
up-flow and 7\% in the down-flow (Van Calster et al., 2017). Combinations of messaging and design enhancements were generally more effective in inducing stair use than a singular approach using colors, designs, banners, posters or video messages (Van Calster et al., 2017; Van Hoecke et al., 2018). The reasons for these behavioral changes among some individuals remain little explored.

In many public settings, the mechanical alternatives of escalator and elevator are often available and prominently positioned. In many newer shopping center developments, the visible stairs are eliminated. In some recent projects, the stairway has gained in size, central position and design elaboration, along with the mechanical systems. In some cases, the stairway becomes the dominant feature of the landscape setting for new worksite buildings and can also be a central feature of the internal organization of the building. Exposing the stairs has often brought increased attention to the details of the design and the quality of the materials. Stairs can be integrated into the architectural design rather than being treated as a standalone facility. In terms of physical factors possibly impacting stair use we have the metrics of the stairs, relation with the physical context, architectural design and materials. Whether dimensions impact use rate independent of other considerations is not known, nor whether users respond with their feet to aesthetics.

This research focusses on three metrics of stairway design: width, pitch and alignment with regard to the escalator alternative. We also account for relative location of the stairway and escalator, pedestrian volume and height, following previous findings for these factors (Zacharias and Tang, 2016; Zacharias and Ling, 2015).

\section{Literature}

Design intended to promote active living has rarely been evaluated. In the case of a new worksite building, occupants who had previously worked elsewhere increased standing behavior while stairclimbing remained the same (Engelen et al., 2016). Design interventions have involved visual and lighting modifications that transformed stairwells for emergency evacuation into useable systems for travelling between floors (Boutelle et al., 2001; Kerr et al., 2004). Combinations of visual material for point-of-decision prompts supports active choices (Landais et al., 2020), as does the addition of music. Structural interventions that would allow before-after analysis and the uncovering of causes of behavioral change are exceedingly rare and unrepresented in the scientific literature.

The layout of the walking environment has long been shown to impact pedestrian movement choice. Pedestrians tend to maintain heading in their path choices (Dalton, 2003) and also glean and retain most information about the environment from a narrow visual field associated with the heading (Werner and Schmidt 1999). Deviation from heading embodied in the axis of the plan view of the stair and escalator might then explain the tendency to take one or the other. Over multiple environments with a random assignment of facilities, however, the cumulative effect of angular deviation with regard to approach angle should disappear. In the absence of detailed knowledge of the path trajectories of all pedestrians in those environments of choice, it is also possible to consider the impact of the difference in absolute angle of the longitudinal axes of the choices represented by the two facilities. Assuming random assignment, the difference in absolute angle should also be nonsignificant in overall pedestrian choices. It may be, however, that a larger angle confers new meaning on the choice and suggestions about the organization of the environment that twinning the choices does not. To follow up on this possibility, we set up a study that included a range of differences in absolute angles of the longitudinal axes of the twinned stair and escalator choices.

Other elements of layout may also have significant impact on choices. The distance between the base of the stair and escalator is a significant positive contributor to ascending stairs, accounting for $71 \%$ of the variance in the ascending model and $21 \%$ in the descending model for paired facilities in 
the public environment (Zacharias \& Ling, 2015). Stairs nearer the escalator are more likely to be used in descent than is the case for ascent, which may be explained by relative energy expenditure. In the Beijing study, $28.8 \%$ of the variance in ascent is explained by the distance between the facilities, and 6\% in descent (Zacharias \& Tang, 2016). Rate of stair ascent increases linearly as the distance between the facilities increases; also true for descent but at a much lower rate. In public environments with a habitual user group, as represented in these two studies, users not only could see the nearest mechanical or active option but were also likely to be aware of the resulting trajectory when one or the other was chosen. It appears that separating the facilities confers somewhat different meaning of opportunity when faced with these choices. We do not know whether the decision to use a facility was already taken long before the arrival at the point-of-decision.

Alternatively, the point-of-decision at the stairway is between ascending and travelling farther on the same plane, such that the real and known existence of the mechanical option may have less salience in the decision. The real possibility that a stair facility is viewed differently when it is separated from mechanical lift alternatives is worth exploration in the context of active travel promotion.

The width of the stairway is also thought to induce stair climbing but the evidence is limited to transport terminals. In conditions of crowding at the foot of escalators in rail transport terminals, a higher rate of stair use is observed. In Hong Kong, stair users reached $15 \%$ of the flow when the delay for entering the up escalator reached $17.4 \mathrm{~s}, 7.8 \mathrm{~s}$ in the case of descending movement (Cheung \& Lam, 1998). Stair use was related positively to delay. Wider stairs in such transport terminals are associated with a higher rate of stair use since they can accommodate larger flows and reduce delay (Eves et al., 2008). We still lack evidence that wider stairs alone will induce stair climbing, a key motivation for the present research. A wider stair facility increases its visual presence and perhaps its symbolic importance in the environment, which might increase the likelihood of use. In many situations, a wide stairway also makes the escalator more difficult to locate visually, perhaps also provoking a spontaneous decision to climb stairs as the most obvious choice.

The pitch or slope represented by the rise and run of a stair has long been the object of attention by designers. There are substantial variations in pitch in the public environment as designers exploit the possibilities and with expectations of associated experience. Indoor stairways tend to vary less in pitch, when the stairway is also a fire evacuation route, because the slope must fall within a defined building code range. In the meantime, pitch is perceived as greater by older people and women (Proffitt et al., 1995), which probably relates to relative muscle strength. If a steeper pitch might appear more arduous and energy-consuming than a lower one, for a given height, then this perception might translate into a behavioral choice. It is also more difficult to estimate pitch when examining from the top because the subtended angle between top and bottom of the facility is much less than upon approach from the bottom. If perceived angle of pitch is important in the decision to the take the stair, it may be because the stairs appear more comfortable or less arduous. If lower pitch results in a lower riser, then the comfort hypothesis is credible given lower degree of knee flexion (Pincivero et al., 2004). Given the absence of research on voluntary stair climbing as a function of stair pitch, we have included this variable in the present study.

Height to be transcended is always thought to be salient because of the energy needed to raise body weight. In the case of transport terminals, delay is more important than height. In an observation study in Beijing it was found that under conditions of $30 \mathrm{~s}$ of delay, virtually the same proportion of users opt for stairs when the height varies from $2 \mathrm{~m}$ to $10 \mathrm{~m}$ (Li et al., 2014). Increasing height did result in lowered choice in public and shopping environments (Zacharias and Ling, 2015; Zacharias and Tang, 2016) but the effect size was small relative to other factors for the given range of heights. 
Clearly, the stair-escalator choice is not only about utility but reflects a complex assimilation of environmental information in relation to self and intent. Social force may also play a role, in shifting away from over-subscribed choices or imitating the behaviors of others (Mason et al., 2007). Responses in this kind of choice environment are far from deterministic. How we perceive the environment in terms of opportunities, but also how interpretations of elements of that environment are transformed as a function of the shifting frame of reference of the pedestrian, deserve deeper exploration.

Ideally, we could conduct a before-after study of a location or major design change in the facility that would allow us to isolate the particular change in the environment. This opportunity is rare and requires advance warning to be able to conduct the baseline study. In the absence of such controlled intervention, we need to look to cross-sectional study in an attempt to isolate these same variables, while understanding the mechanism requires different study as noted above. Cross-sectional studies allow the identification of associations between such structural interventions and outcomes, where all potential contributory factors can be controlled-the approach taken here.

\section{Aims and Hypotheses}

The present study is intended to uncover the effects of stair design in stair climbing rates where an escalator alternative is available for the same immediate destination. The environments are public or publicly accessible areas in shopping centers, to capture trips that are more likely voluntary and less time-constrained than is the case in worksites. Following the literature, we have three hypotheses, as follows:

1- Stair width is positively associated with stair climbing rate;

2- The greater the angle between the longitudinal axis of the stairway and that of the escalator, the greater the stair use rate (figure 1a);

3- Lower stairway pitch is associated with higher stair rate (figure 1b).

\section{Methods and Materials}

Sampled sites were in 8 commercial districts in Beijing where a stairway was twinned with up and down escalators. The landings at the top of the stairs and escalator were connected at the same plane, as were the landings or floors at the bottom. It was necessary to be able to see the escalator option from the points-of-choice for the stairs and vice versa, to allow for pedestrians who might not be familiar with the particular environment. All stairways and escalators needed to be open to the floors at top and bottom and without doors. There were 21 cases of twinned facilities retained for the current study distributed among the 8 commercial areas. Eight of the cases are within buildings.

It was necessary to sample sites that also represented a range in the independent variables. While looking for representation across a range for each variable, we aimed at heterogeneity in the retained cases.

Permission was obtained from the building operators to conduct the counts at the study sites, while ensuring that observed pedestrians' identities were not identifiable. Stair-escalator pairs were simultaneously video-recorded with the frame fixed on the lower extremities at the bottom of each. There were 18 simultaneous samples of 5 minutes each at 20 locations, and 6 samples for one location, for 366 sets of stair-escalator combinations, and a total volume of 29,982 observed pedestrians. The recordings were conducted in November and December 2019, from 10.30 a.m. to 5.00 p.m. to avoid commuter traffic and possible dense flows. 
Pedestrians were counted entering or leaving the facility by counting those entering the picture frame after the segment begins. The up and down counts for the two facilities were conducted from manual inspection of all of the video record by three individuals. Only one flow direction on one facility was counted at one inspection of the video. The up model had 14,750 data while the down model had 15,232.
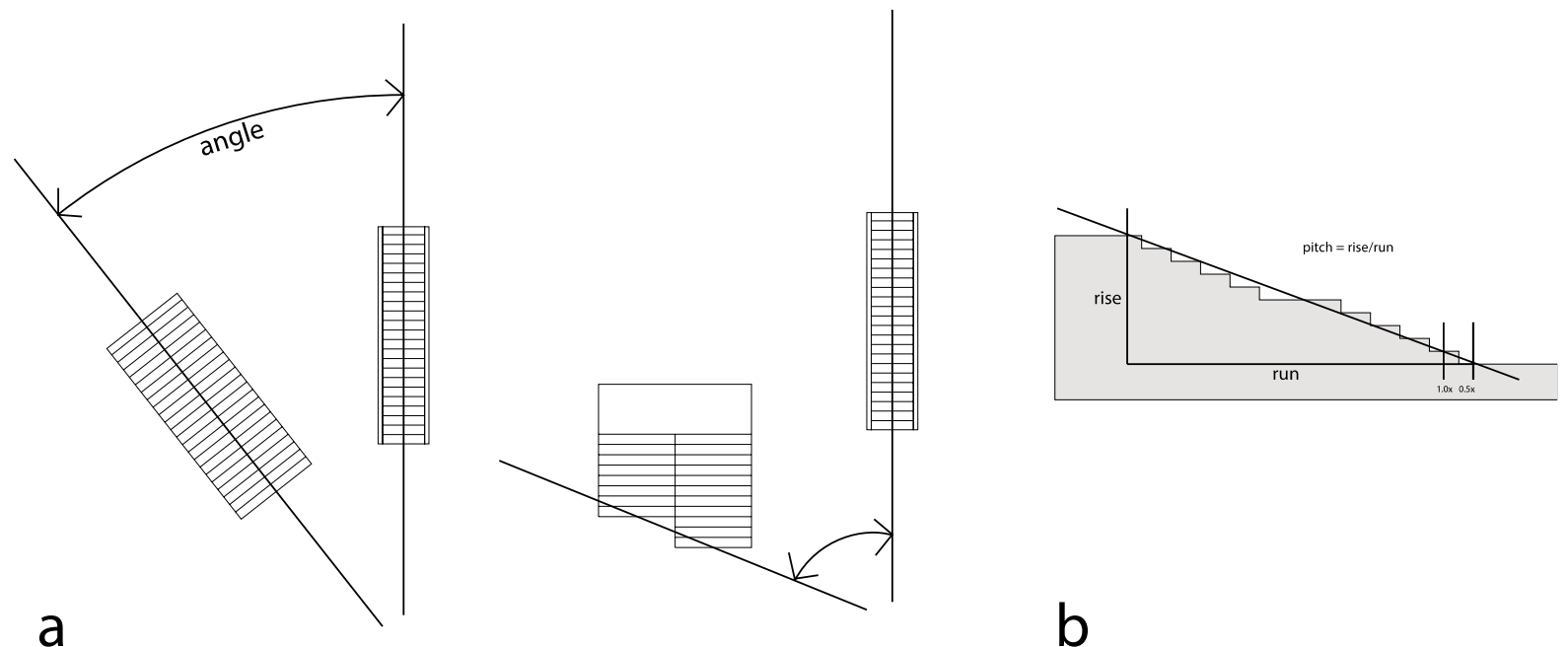

Figure 1. Difference in angle of axis of stair and escalator facilities (a), and stair pitch (b)

The stairs were measured with a steel ruler for their useable width between banisters. Angle was measured as the difference between the angle of the axis of the stair facility and that of the escalator (figure 1a). Slope was measured as the rise divided by the depth of the stair tread, including the depth of a mid-height landing where they occurred (figure 1b). Stairways that included a directional change included the centreline distance on the landing between the successive runs of stairs. In the cases where the width varied from top to bottom of the run, the width at the nearest end of the facility was used. The summary statistics for the facilities are in Table 1. Heights are between adjacent levels and so vary somewhat less than other variables, from 2.4 to $7.5 \mathrm{~m}$. Width varies from 1.0 to $24.0 \mathrm{~m}$ while distance varies from 1.0 to $64.0 \mathrm{~m}$. 
Table 1. Descriptive statistics for study sites

\begin{tabular}{|c|c|c|c|c|c|c|c|c|}
\hline \multirow[b]{2}{*}{ Site } & \multirow{2}{*}{$\begin{array}{l}\text { Height } \\
(\mathrm{m})\end{array}$} & \multicolumn{2}{|c|}{ Width (m) } & \multicolumn{2}{|c|}{ Distance (m) } & \multicolumn{2}{|c|}{ Angle (degrees) } & \multirow{2}{*}{$\begin{array}{l}\text { Pitch } \\
\text { (rise/run) }\end{array}$} \\
\hline & & Bottom & Top & Bottom & Top & $\mathrm{Up}$ & Down & \\
\hline 1 & 4.0 & 2.7 & 2.7 & 7.0 & 30.0 & 180 & 180 & 0.42 \\
\hline 2 & 4.8 & 2.1 & 2.1 & 57.0 & 64.0 & 180 & 180 & 0.50 \\
\hline 3 & 7.1 & 4.5 & 4.5 & 37.5 & 10.0 & 90 & 90 & 0.39 \\
\hline 4 & 7.1 & 4.5 & 4.5 & 30.0 & 10.5 & 90 & 90 & 0.39 \\
\hline 5 & 7.5 & 4.5 & 4.5 & 32.5 & 5.0 & 90 & 90 & 0.39 \\
\hline 6 & 4.8 & 1.2 & 1.2 & 12.0 & 22.0 & 75 & 75 & 0.50 \\
\hline 7 & 6.0 & 3.4 & 3.4 & 15.0 & 14.0 & 90 & 90 & 0.46 \\
\hline 8 & 5.4 & 1.2 & 1.2 & 13.0 & 16.5 & 60 & 60 & 0.53 \\
\hline 9 & 5.6 & 1.0 & 1.0 & 20.5 & 19.0 & 15 & 15 & 0.39 \\
\hline 10 & 5.4 & 1.8 & 1.8 & 13.0 & 25.5 & 75 & 75 & 0.50 \\
\hline 11 & 6.1 & 2.4 & 2.4 & 1.0 & 1.0 & 0 & 0 & 0.48 \\
\hline 12 & 5.4 & 3.3 & 3.3 & 1.0 & 1.0 & 0 & 0 & 0.47 \\
\hline 13 & 4.4 & 2.3 & 2.3 & 1.0 & 32.5 & 0 & 180 & 0.48 \\
\hline 14 & 5.0 & 7.8 & 7.8 & 1.0 & 1.0 & 0 & 0 & 0.34 \\
\hline 15 & 4.6 & 5.4 & 5.4 & 2.0 & 5.0 & 0 & 0 & 0.22 \\
\hline 16 & 4.8 & 4.8 & 4.8 & 2.0 & 5.0 & 0 & 0 & 0.19 \\
\hline 17 & 5.0 & 24.0 & 10.8 & 5.0 & 5.0 & 0 & 0 & 0.21 \\
\hline 18 & 6.9 & 2.5 & 1.4 & 1.0 & 1.0 & 0 & 0 & 0.43 \\
\hline 19 & 5.4 & 2.7 & 2.7 & 1.0 & 1.0 & 0 & 0 & 0.39 \\
\hline 20 & 6.0 & 2.9 & 2.9 & 1.0 & 1.0 & 0 & 0 & 0.36 \\
\hline 21 & 2.4 & 3.9 & 3.0 & 1.0 & 1.0 & 0 & 0 & 0.28 \\
\hline
\end{tabular}

\section{Results}

Stair use rate is $14 \%$ in the up model and $26 \%$ in the down model, while maximum rates are $69 \%$ and $100 \%$ respectively. The standard deviation for the down model is $85 \%$ larger than for the up model, indicating the more active operation of co-factors for the decision to descend. The stair counts for the up model vary from 0 to 93, 0 to 158 for the down model. Escalator counts vary similarly with maximum value at 150 for the up model and 130 for the down model.

An examination of the independent variables includes the correlation matrix (Table 2), where the maximum absolute value is .6, the relation between slope and width. Because this value is not excessively high and all variables are distinct measures, we retain all physical variables-height, width, distance, angle and slope. Dependent variables are the 5-minute counts expressed as a percentage of all uni-directional travellers who use the stairs.

The hierarchical regression allows us to detect the effects of adding successively the independent variables into the model (Table 3). It is seen that SEE continues to decline as variables are added, with negligible change in $\mathrm{F}$, which confirms the separate contributions of each variable. The biggest effect in climbing stairs is stairway width (.594), accounting for upwards of $20 \%$ of variance. The other design elements are also significant in the ascent model, with angle (.263) accounting for about $2 \%$ of variance and pitch about $1 \%$. The higher the pitch, the lower the climb rate. For the down model, stairway width (.328) is second only to distance between choices in effect and accounts for about $10 \%$ of variance. Angle and pitch together account for about $10 \%$ of variance. In this model, distance still accounts for $29 \%$ of stair-climbing and $24 \%$ of descending. 
The coefficients suggest evident effects on stair ascent rates at manipulable architectural scales. The addition of $1 \mathrm{~m}$ or less in stairway width has major positive effect which was not the consequence of pedestrian flow levels associated with the dimensions of the facility. Pedestrian flow had negligeable impact overall. Design, represented by angular difference between the axes of the two facilities and stairway pitch, also had effects in the ascent and especially the descent models.

In summary, with reference to the stated hypotheses of this study,

1- Stairway width is positively associated with stair ascent and descent rates;

2- As the angle between the longitudinal axis of the stairway and that of the escalator increases, stair climbing rate also increases, as does stair descending;

3- Lower stairway pitch is associated with slightly higher stair rate in both ascent and descent models. In this study, it was more difficult to detect the effect of this variable because it often accompanies stair width.

Pedestrian flow was not a factor in the choice because it did not reach a level causing delay. In these conditions of relatively unconstrained decision-making, the choice of the stairs is also voluntary. Together with the other features of the layout, clearly it is worthwhile giving more prominence in the plan to stair facilities in the effort to promote stair climbing.

Table 2. Correlation matrix of independent variables in ascent and descent models

\begin{tabular}{|c|c|c|c|c|c|c|c|}
\hline Ascent model & 1 & 2 & 3 & 4 & 5 & 6 & 7 \\
\hline 1. ascent rate & - & $.192^{* *}$ & $.462^{* *}$ & $.492 * *$ & $.447 * *$ & $-.172^{* *}$ & $.212^{* *}$ \\
\hline 2. height & $.192 * *$ & - & -.086 & $.369 * *$ & $.217 * *$ & $.265^{* *}$ & -.095 \\
\hline 3. stair width & $.462^{* *}$ & .086 & - & $-.188 * *$ & $-.226 * *$ & $-.600 * *$ & -.061 \\
\hline 4. distance & $.492^{* *}$ & $.369 * *$ & $-.188^{* *}$ & - & $.846^{* *}$ & $.316^{* *}$ & $.474 * *$ \\
\hline 5. angle & $.447 * *$ & $.217 * *$ & $-.226 * *$ & $.846^{* *}$ & - & $.450 * *$ & $.547 * *$ \\
\hline 6. pitch & $-.172 * *$ & $.265^{* *}$ & $-.600 * *$ & $.316^{* *}$ & $.450 * *$ & - & $.246^{* *}$ \\
\hline 7. pedestrian vol. & $.212^{* *}$ & -.095 & -.061 & $.474 * *$ & $.547 * *$ & $.246^{* *}$ & - \\
\hline \multicolumn{8}{|l|}{ Descent model } \\
\hline 1. descent rate & - & $-.135^{* *}$ & $.348^{* *}$ & $.354 * *$ & $.410 * *$ & $-.218^{* *}$ & $.250 * *$ \\
\hline 2. height & $-.135^{* *}$ & - & -.033 & $-.183 * *$ & .057 & $.265^{* *}$ & -.071 \\
\hline 3. stair width & $.348^{* *}$ & -.033 & - & $-.349 * *$ & $-.269 * *$ & $-.696 * *$ & $-.135^{* *}$ \\
\hline 4. distance & $.354 * *$ & $-.183^{* *}$ & $-.349 *$ & - & $.822 * *$ & $.481 * *$ & $.691 * *$ \\
\hline 5. angle & $.410 * *$ & .057 & $-.269 *$ & $.822 * *$ & - & $.523^{* *}$ & $-.435 * *$ \\
\hline 6. pitch & $-.218 * *$ & $.265^{* *}$ & $-.696^{*}$ & $.481 * *$ & $.523^{* *}$ & - & $.265^{* *}$ \\
\hline 7. pedestrian vol. & $.160 * *$ & -.071 & $-.135^{*}$ & $.691 * *$ & $.435^{* *}$ & $.265^{* *}$ & - \\
\hline
\end{tabular}

${ }^{*} \mathrm{p}<.05 ;{ }^{*} \mathrm{p}<.01$ 
Table 3. Hierarchical linear regression for 6 variables as predictors of stairway choice

\begin{tabular}{|c|c|c|c|c|c|c|}
\hline Variable & $\begin{array}{l}\text { Regression } \\
\text { Coefficient }\end{array}$ & SEE & $\begin{array}{l}\text { Standard. } \\
\text { Coefficient }\end{array}$ & $\begin{array}{l}\text { Char } \\
\mathrm{R}^{2}\end{array}$ & $\begin{array}{l}\text { in } \ldots . . . . . \\
\text { F-value }\end{array}$ & Sig. \\
\hline \multicolumn{7}{|c|}{ Model 1: Ascending } \\
\hline height & $.028^{* *}$ & .008 & .192 & .037 & $13.919 * *$ & .789 \\
\hline height & $.035^{* *}$ & .007 & .233 & .230 & $114.125^{* *}$ & .000 \\
\hline stairway width & $.017 * *$ & .002 & .482 & & & .000 \\
\hline height & .003 & .006 & .022 & .294 & $242.826^{*}$ & .549 \\
\hline stairway width & $.020 * *$ & .001 & .575 & & & .000 \\
\hline distance & $.006 * *$ & .000 & .592 & & & .000 \\
\hline height & .008 & .006 & .052 & .019 & $16.035 * *$ & .166 \\
\hline stairway width & $.021 * *$ & .001 & .594 & & & .000 \\
\hline distance & $.004 * *$ & .001 & .364 & & & .000 \\
\hline angle & $.001 * *$ & .000 & .263 & & & .000 \\
\hline height & $.012 *$ & .006 & .082 & .008 & $7.027 * *$ & .036 \\
\hline stairway width & $.019 * *$ & .002 & .527 & & & .000 \\
\hline distance & $.003 * *$ & .001 & .314 & & & .000 \\
\hline angle & $.001 * *$ & .000 & .341 & & & .000 \\
\hline pitch & $-.219 * *$ & .083 & -.130 & & & .008 \\
\hline height & .008 & .006 & .056 & .004 & $3.840^{*}$ & .168 \\
\hline stairway width & $.019 * *$ & .002 & .539 & & & .000 \\
\hline distance & $.004 * *$ & .001 & .337 & & & .000 \\
\hline angle & $.001 * *$ & .000 & .369 & & & .000 \\
\hline pitch & $-.194 * *$ & .083 & -.115 & & & .020 \\
\hline pedestrian vol. & .000 & .000 & -.084 & & & .051 \\
\hline
\end{tabular}

Model 2: descending

\begin{tabular}{lcccccc} 
height & $-.028^{* *}$ & .011 & -.135 & .018 & $6.733^{* *}$ & .010 \\
\hline height & $-.025^{* *}$ & .010 & -.123 & .118 & $49.659^{* *}$ & .012 \\
stairway width & $.034^{* *}$ & .005 & .344 & & & .000 \\
\hline height & -.004 & .009 & -.019 & .242 & $140.996^{* *}$ & .655 \\
stairway width & $.053^{* *}$ & .004 & .535 & & & .000 \\
distance & $.008^{* *}$ & .001 & .537 & & & .000 \\
\hline height & $-.022^{* *}$ & .009 & -.109 & .047 & $29.293^{* *}$ & .014 \\
stairway width & $.051^{* *}$ & .004 & .517 & & & .000 \\
distance & $.003^{* *}$ & .001 & .178 & & .026 \\
angle & $.002^{* *}$ & .000 & .509 & & .000 \\
\hline height & -.003 & .009 & .014 & .049 & $33.472^{* *}$ & .763 \\
stairway width & $.030^{* *}$ & .006 & .297 & & & .000 \\
distance & $.003^{* *}$ & .001 & .219 & & .004 \\
angle & $.002^{* *}$ & .000 & .509 & & & .000 \\
pitch & $-.882^{* *}$ & .153 & -.379 & & & .000 \\
\hline height & .003 & .009 & .016 & .012 & $8.662^{* *}$ & .721 \\
stair width & $.033^{* *}$ & .006 & .328 & & & .000 \\
distance & $.007^{* *}$ & .002 & .426 & & & .000 \\
angle & $.002^{* *}$ & .000 & .415 & & & .000 \\
pitch & $-.865^{* *}$ & .151 & -.371 & & & .000 \\
pedestrian vol. & $-.001 * *$ & .000 & -.171 & & & .003 \\
\hline \hline
\end{tabular}

${ }^{*} \mathrm{p}<.05 ;{ }^{*} \mathrm{p}<.01$ 


\section{Discussion}

It is widely held that utility should prevail in the decision to ascend stairs because of the precondition of energy expenditure, if we accept that utility dominates decision-making in that particular context. High variation in stair ascent rates across environments and as a function of plan innovations, as well as individual susceptibility to suggestions of behavioral change, suggest that not all such decision-making refers primarily to utility considerations.

In the present study, we focussed on physical properties of the facilities themselves as possible explanations for stair climbing or descending, following many suggestions in the literature and pervasive architectural practice today. Width of stairway was associated with a shift of traffic from the escalator under conditions of time pressure in public transport (Cheung \& Lam, 1998; Eves et al., 2008). Others would like to know what intrinsic properties of the facility impact choice. Designers might like to know the relative effectiveness of a wide stair facility in a building project and what resources to devote to it. For the present investigation, we used the metric of tread width. This metric alone accounted for a substantial proportion of the variance in stair climbing rate. Why this should be is worthy of investigation. For example, does the larger part of the visual field occupied by such a facility have a direct effect on the decision, or does its larger size confer some intrinsic value in the choice calculation? The long-observed tendency of pedestrians to deviate from utility-maximizing spatial behaviors while on excursion is perhaps an indication of behaviors in other decision contexts (Gärling \& Gärling, 1988). The suggestion here is of a mediating mechanism whereby seemingly incommensurable entities-time, pleasure, and physical exertion, for example-are assimilated with a decision outcome. Whether this decision is entirely spontaneous is doubtful among frequent visitors to such public places, because they surely would have weighed the various factors, if only subliminally, before taking action. Some degree of spontaneity in the decision is also suggested since the choices clearly attach to discrete properties of the immediate environment.

The other element of layout examined here is angle between the longitudinal axes of the stair and escalator. When stairs and escalator are adjacent and parallel to each other they clearly represent a single idea. A deviation from $0^{\circ}$ is a complexification of the plan at the very least, and also expands origin and destination areas for the facilities. Whether this additional complexity of layout and a possible dissociation of component elements is responsible for the observed higher levels of use could be added to the above-mentioned call for psychometric measures. There is a small but significant contribution from lower pitch as well, perhaps for similar perceptual reasons.

Our research design tried to avoid high-flow conditions at commuting times while ensuring that there was adequate flow for measurement purposes. The intention to minimize the effect of pedestrian flow on the choice, where higher flows engage the experience or anticipation of delay or crowding, was achieved. The volume of traffic has a negligible impact on the result, but it is also worth noting that at moderate or low flows, the case of the great majority of public environments, volume-flow has little or no impact on this particular decision-making.

The present study also identified distance between the foot or top of the paired facilities as the most important factor in decision-making, in keeping with the previous studies examining this variable (Zacharias \& Tang, 2016; Zacharias \& Ling, 2015). The suggestion here is that there is something more about this feature of the plan of a building than simply the metric distance. The separation of the facilities has to be realized in a plan which may alter not only the flows of people but how the space and the opportunities it affords are perceived by the visitor. This is a complex matter because it concerns how a multi-level plan is perceived in relation to a planned or spontaneous trip. 
The accumulating studies on the environmental factors in stair-climbing behavior are actionable. If the planning concept were to spring from an understanding of human response in terms of spatial behavior, there is considerable potential to shift spatial behaviors to active modes. In this way, spatial design can be a direct contribution to public health by raising proportion of people using stairs over their mechanical counterparts.

\section{Conclusion}

The three new variables of stairway width, angular difference in longitudinal axis and stairway pitch are all significant in stair climbing rate. Together they account for about $23 \%$ of the variance in ascent rate and $20 \%$ in descent. The coefficients for width in the ascent (.539) and descent (.328) models suggest significant effects for typical stairway facilities averaging $4.0 \mathrm{~m}$ in width at the 21 sites of paired facilities. Layout is important as measured by angular difference with somewhat greater effects in the descent model (.409) than for ascent (.293). Higher pitch also has negative effect on stair climbing and descending rates. The relatively small dampening effect of height on this choice might also be explained by little variance in response for heights of up to $10 \mathrm{~m}$. This height is rarely exceeded between levels in the public and publicly accessible indoor environments.

The five variables under consideration in this study all point to clear positive effects in terms of active transport in the public environment. The three findings of width, angle and pitch are all new in the still-scarce literature on active choices at the scale of the point of decision. While it remains to better understand the perceptual underpinnings of these spatial movement decisions, they could be operationalized in planning and design now. The integration of these concepts in spatial planning is particularly important as local governments try to make their cities more hospitable to active lifestyles with consequent benefits for public health over the whole population.

\section{Acknowledgements}

\section{References}

Allais, Olivier, Bazoche, Pascale, Teyssier, Sabrina (2017). Getting more people on the stairs: the impact of point-of-decision prompts. Social Science \& Medicine 192, 18-27.

Allison, Mary K., Baglole, Jessica H., Martin, Brian J., MacInnis, Martin J., Gurd, Brendon J. \& Gibala, Martin J. (2017). Brief intense stair climbing improves cardiorespiratory fitness. Medical Science and Sports Exercise 49, 2, 298-307.

Åvitsland, Andreas, Solbraa, Ane Kristiansen \& Riiser, Amund (2017). Promoting workplace stair climbing: sometimes, not interfering is the best. Archives of Public Health 75, 2. doi: 10.1186/s13690-016-0170-8

Bellicha, Alice, Kieusseian, Aurélie, Fontvieille, Anne-Marie, Tataranni, Antonio, Copin, Nane, Charreire, Hélène \& Oppert, Jean-Michel (2016). A multistage controlled intervention to increase stair climbing at work: effectiveness and process evaluation. International Journal of Behavioral Nutrition and Physical Activity 13, 47. doi: 10.1186/s12966-016-0371-0

Boutelle, K.N., Jeffery, R.W., Murray, D.M., \& Schmitz, M.K. (2001). Using signs, artwork, and music to promote stair use in a public building. American Journal of Public Health 91, 12, 20042006.

Cheung, C. Y., \& Lam, W. H. K. (1998). Pedestrian route choices between escalator and stairway in MTR stations. Journal of Transportation Engineering 124, 277-285. 
Dalton, Ruth Conroy (2003). The secret is to follow your nose-route path selection and angularity. Environment and Behavior, 35, 1, 107-131. doi: 10.1177/0013916502238867

Engelen, L., Dhillon, H.M., Chau, J.Y., Hespe, D. \& Bauman, A.E. (2016). Do active design buildings change health behaviour and workplace perceptions? Occupational Medicine 66, 408411. doi: 10.1093/occmed/kqv213

Eves, Frank F., Lewis, Amanda L., \& Griffin, Carl (2008). Modelling effects of stair width on rates of stair climbing in a train station. Preventive Medicine 47, 270-272.

Hongu, Nobuko, Shimada, Mieko, Miyake, Rieko et al. (2019). Promoting stair climbing as an exercise routine among healthy older adults attending a community-based physical activity program. Sports 7, 1, 23.

Jennings, Cally A., Yun, Lira, Loitz, Christina C., Lee, Eun-Young, Mummery, \& Kerry W. (2017). A systematic review of interventions to increase stair use. American Journal of Preventive Medicine 52, 1, 106-114.

Kerr, N.A., Yore, M.M., Ham, S.A., \& Dietz, W.H. (2004). Increasing stair use in a worksite through environmental changes. American Journal of Health Promotion 18, 4, 312-315.

Landais, Lorraine L., Damman, Olga C., \& Schoonmade, Linda J. (2020). Choice architecture interventions to change physical activity and sedentary behavior: a systematic review of effects on intention, behavior and health outcomes during and after intervention. International Journal of Behavioral Nutrition and Physical Activity 17, 1, 47.

Li, Qian, Ji, Changxu, Jia, Limin, \& Qin, Yong (2014). Effect of height on pedestrian route choice between stairs and escalator. Discrete Dynamics in Nature and Society 965305. doi: $10.1155 / 2014 / 965305$

Mason, W., Conrey, F., \& Smith, E. (2007). Situating social influence processes: Dynamic, multidirectional flows of influence within social networks. Personality and Social Psychology Review 11(3), 279 (2007)

Pincivero, D.M., \& Campy, R.M. (2004). The effects of interval length and training on quadriceps femoris muscle. Part I: Knee extensor torque and muscle fatigue. Journal of Sports Medicine and Physical Fitness 44, 2, 111-118.

Proffitt, D.R., Bhalla, M., Gossweiler, R., et al. (1995). Perceiving geographical slant. Psychonomic Bulletin \& Review 2, 4, 409-428.

Puig-Ribera, Anna, Señé-Mir, Anna M., Taylor-Covill, Guy A.H., De Lara, Núria, Carroll, Doublas, Daley, Amanda, Holder, Roger, Thomas, Erica, Milà, Raimon \& Eves, Frank F. (2019). Signage interventions for stair climbing at work: more than 700,000 reasons for caution. International Journal of Environmental Research and Public Health 16, 3782. doi: 10.3390/ijerph16193782

Soler, Robin et al., (2010). Point-of-decision prompts to increase stair use - a systematic review update. American Journal of Preventive Medicine, 38, 2S, S292-S300.

Stenling, Andreas, Moylan, Adam, Fulton, Emily and Machado, Liana (2019). Effects of a brief stairclimbing intervention on cognitive performance and mood states in healthy young adults. Frontiers in Psychology 10, 2300. doi: 10.3380/fpsyg.2019.02300 
Van Calster, L., Van Hoecke, A.-S., Octaef, A., Boen, F. (2017). Does a video displaying a stair climbing model increase stair use in a worksite setting? Public Health, 149, 11-20.

Van Hoecke, Ann-Sophie, Seghers, Jan, Boen, Filip (2018). Promoting stair climbing in a worksite and public setting: are footprints enough? American Journal of Health Promotion, 32, 3, 527-535.

Werner S, Schmidt K, 1999, “Environmental reference systems for large-scale spaces” Spatial cognition and computation $1447-473$

Zacharias, J. and Ling, R. (2014). Choosing between stairs and escalator in shopping centers-the impact of location, height and pedestrian volume. Environment \& Behavior 47, 6, 694-709. doi: $10.1177 / 0013916513520418$

Zacharias, J. and Tang, B. (2015). Choosing between stairs and escalators in China: the impact of location, height and pedestrian volume. Preventive Medicine Reports 2, 529-532. 